\title{
Farming by soil in Europe: status and outlook of cropping systems under different pedoclimatic conditions
}

\author{
Gergely Tóth ${ }^{1,2}$, Tamás Kismányoky ${ }^{1}$, Piroska Kassai ${ }^{\text {Corresp., } 1}{ }^{1}$, Tamás Hermann ${ }^{1}$, Oihane Fernandez-Ugalde ${ }^{3}$, \\ Brigitta Szabó ${ }^{2}$ \\ ${ }^{1}$ Georgikon Faculty, University of Pannonia, Keszthely, Hungary \\ 2 Institute for Soil Sciences and Agricultural Chemistry, Centre for Agricultural Research, Budapest, Hungary \\ 3 Directorate D - Sustainable Resources, European Commission, Joint Research Centre, Ispra, Italy \\ Corresponding Author: Piroska Kassai \\ Email address: kassai.piroska@georgikon.hu
}

\section{Background}

Despite of the importance of soils in agronomy, to date no comprehensive assessment of cropping in Europe has been performed from the viewpoint of the soil variability and its relationship to cropping patterns. In order to fill this knowledge gap, we studied the cropping patterns in different soils of European climate zones with regards to the shares of their crop types in a comparative manner. The study highlights the main features of farming by soil in Europe. Farming by soil in this context means the consideration of soil characteristics when selecting crop types and cropping patterns.

\section{Methods}

We first assessed the dissimilarity between the cropping compositions of different pedoclimatic zones in Europe. Next, we assessed the differences of crop distribution in the climate zones by soil types and main crop types, by analyzing the degree of association of crops to soil types. A detailed country scale assessment was performed using crops-specific soil productivity maps and land use survey data from Hungary.

\section{Results}

Results suggest, that in general, farmers consciously take pedoclimatic condition of farming into account when selecting their cropping patterns. In other words, farming by soil is a common practice in the different climatic regions of Europe. However, we have strong reasons to believe that soil suitabilitybased cropping is not practiced to its full potential over the continent. For example finding of our European assessment suggests that production areas of legumes are not always optimized for the local pedoclimatic conditions in some zones. Findings also underline that economic drivers are decisive, when farmers adopt their cropping (eg. oil crops on Albeluvsiols in Europe). Win-win situations of economic considerations and soil suitability based management are observed in all pedoclimatic zones of Europe. The country analysis shows that cropping is progressively practiced on more suitable areas, depending also the crop tolerance to variable pedoclimatic conditions In conclusion, we can assume that pedoclimatic conditions of cropping are respected in most of Europe and farmers crop according to edaphic conditions whenever economic considerations do not override the ecological concerns of farming. 
1 Farming by soil in Europe: status and outlook of

2 cropping systems under different pedoclimatic

3 conditions

4

5

6 Gergely Tóth ${ }^{1,2}$, Tamás Kismányoky ${ }^{1}$, Piroska Kassai ${ }^{1}$, Tamás Hermann ${ }^{1}$, Oihane Fernandez-

7 Ugalde $^{3}$, Brigitta Szabó ${ }^{2}$

8

$9 \quad{ }^{1}$ University of Pannonia, Georgikon Faculty, Keszthely, Hungary

2 Institute for Soil Sciences and Agricultural Chemistry, Centre for Agricultural Research,

dapest, Hungary

$12{ }^{3}$ European Commission, Joint Research Centre, Directorate D - Sustainable Resources, Ispra, 13 Italy

Corresponding Author:

Piroska Kassai ${ }^{1}$

16 Deák Ferenc Street, Keszthely, 8360, Hungary

Email address: piroska.kassai@georgikon.hu

\section{Abstract}

\section{Background}

Despite of the importance of soils in agronomy, to date no comprehensive assessment of cropping in Europe has been performed from the viewpoint of the soil variability and its relationship to cropping patterns. In order to fill this knowledge gap, we studied the cropping patterns in different soils of European climate zones with regards to the shares of their crop types in a comparative manner. The study highlights the main features of farming by soil in Europe. Farming by soil in this context means the consideration of soil characteristics when selecting crop types and cropping patterns.

\section{Methods}

We first assessed the dissimilarity between the cropping compositions of different pedoclimatic zones in Europe. Next, we assessed the differences of crop distribution in the climate zones by soil types and main crop types, by analyzing the degree of association of crops to soil types. A detailed country scale assessment was performed using crops-specific soil productivity maps and land use survey data from Hungary.

\section{Results}

Results suggest, that in general, farmers consciously take pedoclimatic condition of farming into account when selecting their cropping patterns. In other words, farming by soil is a common practice in the different climatic regions of Europe. However, we have strong reasons to believe that soil suitability-based cropping is not practiced to its full potential over the continent. For 
40 example finding of our European assessment suggests that production areas of legumes are not 41 always optimized for the local pedoclimatic conditions in some zones. Findings also underline 42 that economic drivers are decisive, when farmers adopt their cropping (eg. oil crops on

43 Albeluvsiols in Europe). Win-win situations of economic considerations and soil suitability 44 based management are observed in all pedoclimatic zones of Europe. The country analysis shows 45 that cropping is progressively practiced on more suitable areas, depending also the crop tolerance 46 to variable pedoclimatic conditions

47 In conclusion, we can assume that pedoclimatic conditions of cropping are respected in most of 48 Europe and farmers crop according to edaphic conditions whenever economic considerations do 49 not override the ecological concerns of farming.

50

\section{Introduction}

52 Sustainable agriculture aims to maintain productivity by optimizing the use of locally available

53

54

55

56

57

58

59

60

61

62

63

64

65

66

67

68

69

70

71

72

73

74

75

76

77

78

79 resources, including climatic and edaphic resources and reducing the use of external and nonrenewable inputs. Improving the synergies between soil qualites and cropping patterns is key to achieve this aim. While the principle of optimization of plant production for local conditions is widely recognized (Wezel et al. 2014), there is little knowledge about its practice in Europe. According to the common scientific understanding, the importance of economic and policy factors play a key role in the farmers' decision, when selecting the most appropriate crop type (Tilman et al. 2002). Farmers go for profit, even if sustainability of the production is among their considerations. Demand of the world commodity market and subsidy schemes of the Common Agricultural Policy influences the profitability of cropping in the European Union, thus the planning of the entire cropping system (van Zanten et al. 2014). While economic and policy factors delimit the farmers' optimization strategies, the characteristics of underlying ecological resources set the boundary conditions for farming. Intensive agricultural management can melt away much of the difference in the suitability for cropping different plants on given site, at least to a degree which turns the ecologically less suitable alternative to an economically more profitable one (Ittersum and Rabinge 1997). Hence, farming by soil can be part of the solution for sustainable intensification, which targets high economic profit with resource use optimization and conservation (Pretty 1997). Farming by soil in this context means the selection of the most suitable cropping system for a given soil. Application of the most appropriate soil management technique is the other main component of soil specific farming and has received more attention with the emergence of precision agriculture in the past decades (Bongiovanni and LowenbergDeboer 2004). However, so far little scientific research has been made to assess the relationship between soil quality and composition of crops.

Our analysis aimed to fill this information gap and targeted to reveal the relationship between cropping practices and soil conditions in Europe and with a detailed assessment in Hungary. Soil quality, including water management and nutrient availability is an essential, yet quite variable property of soil types, therefore we performed our analysis for Europe based on soil types, defined as Reference Soil Groups (FAO et al. 1998). To enable integrated analysis of complexity 
80

81

82

83

84

85

86

87

88

89

90

91

92

93

94

95

96

97

98

99

100

101

102

103

104

105

106

107

108

109

110

111

112

113

114

115

116

117

118

119

in the climate-soil-crop system, cropping pattern by soil types were assessed in the main climate zones. In a country analysis, where (i) crop-specific soil productivity maps, showing the suitability of cropping and (ii) field survey data on major crops were available, we assessed the crop distribution of major crop types on soils with different productivity levels.

Our analysis focused on land-based agriculture, i.e. large scale open-air arable farming and did not assess differences in management practices. While recognizing the influence of land management on the success of farming our current interest was solely in testing the hypothesis of existing spatial relationship between soils and farming systems in the continent of Europe and on a country scale in Hungary.

\section{Materials \& Methods}

2.1 Identification of cropping system in pedoclimatic zones of Europe using spatial datasets

Spatial units of the analysis were the pedoclimatic zones (PCZs), which are unique combinations of soil type and climate. Pedoclimatic zones were delineated by overlapping the layer of European climatic zones geodatabase, as reclassified for soil productivity evaluation (Tóth et al. 2013 based on Hartwich et al. 2005; see Figure 1.) with the layers of Reference Soil Groups (RSGs, FAO 1998) of the European Soil Database (ESDB, EC 2003). Physical area for crops was calculated for each pedocimatic zone using the MapSpam 2005 dataset developed by You et al. (2014). Spatial precision of the MapSpam data was assessed by Joglekar et al (2019) and their findings confirm the adequacy for a using this data together with the ESDB data, for continental scale analysis. As a result, we created geodata layers containing the information of the physical area covered by each crop in each pedoclimatic zones of Europe. We focused on the following cropping system classes: cereals (barley, millet pearl, millet small, sorghum, wheat and other cereals), maize, legumes (bean, chickpea, cowpea, lentil, pigeon pea, and other pulses), oil crops (rapeseed, sesame, soybean, sunflower and other crops) and root crops (cassava, potato and other roots and tubers).

2.2 Statistical analysis to reveal spatial characteristics of crop systems in relation to pedoclimatic conditions in Europe

The analysis of crop systems in the pedoclimatic zones of Europe was performed by main climate zones, i.e. the climatic component of the pedoclimatic zones. Similarities and differences of the distribution of crop types on different soils within climatic zones were assessed in a comparative manner using dissimilarity analysis.

We first assessed the dissimilarity between the cropping compositions of different pedoclimatic zones. 
120 Dissimilarity was calculated with 'vegan' package (Oksanen et al., 2017). We computed Bray121 Curtis dissimilarity index with vegan R package to quantify dissimilarity of RSGs based on the 122 distribution of their cropping systems in pairwise comparisons. The dissimilarity index reaches 123 its maximum value one when there are no shared cropping system classes between two compared 124 RSGs. Analysis has been performed for each climatic zones separately. Function decostand was 125 used to standardize the values.

126 The matrix of dissimilarity index shows the differences between the compositions of cropping 127 systems of the compared PCZs by climate zone. The darker the cell in the matrix, the larger the 128 difference between the cropping compositions of the two compared PCZs (soil types) within the 129 given climate zone.

130 Next, we assessed the differences of crop distribution in the climate zone by soil types (RSGs) 131 and main crop types, by analyzing the degree of association of crops to soil types (RSGs).

132

133

134

135

136

137

138

139

140

141

142

143

144

145

146

147

148

149

150

151

152

153

154

155

156

157

158 Association was analyzed with 'vcd' R package (Meyer at al., 2016). Association plot (Meyer et al., 2003): ,reject the null hypothesis of independence of the two categorical variables when there are residuals which are too extreme, i.e., not close enough to zero. This is the well-known $\chi$ 2 test for independence in 2 -way tables. When the $\chi 2$ test statistic turns out to be significant for some data, it seems natural to go back to its components, i.e., the residuals, for a more detailed analysis. Association plots visualize the table of Pearson residuals (Zeileis et al., 2007, Meyer et al., 2006): each cell is represented by a rectangle that has (signed) height proportional to the corresponding Pearson residual and width proportional to the square root of the expected counts. The highlighted cells are those with residuals individually significant at approximately the $5 \%$ and $0.01 \%$ level. The main purpose of the shading is not to visualize significance but the pattern of deviation from independence."

We analyzed with Chi-squared test (Everitt and Hothorn, 2010) if RSGs are significantly different regarding the distribution of the farming systems. Test has been performed on each RSG pairs.

Those soil types are considered, which occupy at least $1 \%$ of the area of the climate zone and of which at least $10 \%$ is cultivated.

\subsection{Analysis of crop distribution by cropland soil productivity in Hungary}

The favorable conditions of data availability from field level crop-specific soil productivity maps and crop data from ground survey enabled to extend our analysis both regarding spatial and thematic accuracy within one European country, namely in Hungary. Plant-specific soil productivity maps with $100 \mathrm{~m}$ spatial resolution were used to characterize the suitability of crop production. Wheat, maize and sunflower productivity maps based on Tóth (2009) are available for the whole of the cropland area of the country as composed by Tóth et al (2018). Cropland areas were classified on a scale 1-100 based on the degree of suitability 
159

160

161

162

163

164

165

166

167

168

169

170

171

172

173

174

175

176

177

178

179

180

181

182

183

184

185

186

187

188

189

190

191

192

193

194

195

196

197

provided for growing major crops, 1 indicating the least productive and 100 is the most productive land (Fig. 2).

Spatially explicit wheat, maize and sunflower observations collected during the Land Use/Cover Area frame Survey (LUCAS) campaigns in 2009, 2012 and 2015 (Eurostat 2020) were used to indicate cropping patterns on croplands in Hungary. 1247 wheat, 1495 maize and 940 sunflower crop fields were observed in Hungary during the three campaigns. Data of the crop observations were superimposed on the crop-specific productivity maps.

Share of crop observations by soil productivity classes (low, medium, high, very high, including land with productivity scores 1-40, 40-60, 60-80 and 80-100 respectively) were calculated and number of cases were compared among classes.

All spatial analysis was performed in ArcGIS 10.4.

\section{Results}

3.1. Crop systems in relation to pedoclimatic conditions of the Atlantic climate zone According to the statistical comparison (Table 1) displayed also in the evaluation matrix (Fig. 3), cropping pattern of Histosols differs from those on most other soil types except for Fluvisols and Podzols to the greatest extent. Furthermore the cropping pattern of Albeluvisols is significantly different from those of Arensols, while the cropping pattern of Arenosols is also significantly different from that of Fluvisols (besides Albeluvisols and Histosols).

The difference in the pattern of Histosol cultivation is largely due to the relatively high share of root crops on this soil type, which is cultivated on a significantly higher share of the area of this soil than on other soil types in the Atlantic climate zone (Fig. 4). Histolsols are soils of loose structure, which is optimal for growing root crops. Therefore favoring root crops on this soil can be considered as good agronomic practice. According to our findings root crops are given preference over maize, and to some extent oil crops on these soils. Potato and sugar beet are predominant among root crops of the climate zone. Both crops are selective in their fore crops and may return to the rotation after 4 years. The high spatial extent of root crops on Histosols suggest that farmers aim the maximum capacity of root crop (potato and sugar beet) production on these soils, considering agronomic possibilities.

On Albeluvisols areas proportionally more oil corps (rapeseed) and maize are grown than on Arenoslos and Histosols. In the meantime the proportional areas of root crops and cereals are smaller. As Albeluvisols are generally low fertility soils not particularly suitable for arable cropping, the relatively higher share of cash crops may be a result of intensive cultivation driven by economic incentives, rather than a search for the most suitable crops. 
198 Dominancy of cereals on Arenosols can be explained by the advanced technologies of high

199

200

201

202

203

204

205

206

207

208

209

210

211

212

213

214

215

216

217

218

219

220

221

222

223

224

225

226

227

228

229

230

231

232

233

234

235

236

237

intensity farming for these crops. Moisture availably, which is often the limiting factor for cereal cultivation is secured under the Atlantic climate. Easy workability and weed control along with well-planned nutrient management can secure high returns from cereals in this pedoclimatic zone.

3.2. Crop systems in relation to pedoclimatic conditions of the Sub-Oceanic climate zone Cropping on Podzols and Gleysols is somewhat different from those on the rest of the soil types (Figs. 3, 4). A higher share of cereals and lower share of oil crops is observed in the cultivation pattern of these two soils in the Sub-Oceanic climate zone. However, these differences are not significant. Nevertheless, cultivation of cereals on Podzols is successful if moisture is available and fertilization is adequate. Both conditions are given in this climate zone and its countries with agriculture of advanced technological levels. Rapeseed, which is the predominant oilcrop in the region and which is primarily cultivated for animal feed and also for canola oil, has a need for quality seedbed preparation and high input of nutrients. The easy workability of Podzols would make them optimal for rapeseed production. However, disparity between the high nutrient demand of rapeseed and the low nutrient supply of Podzols can be lessened probably only with such high inputs, which are not economic. Cambisols and to some extent Luvisols, Leptosols and Regosols of the region are more suitable for rapeseed than for more demanding crops like maize, which is reflected in the cultivation share of those soils.

Cereals and oil crops have similar share on Gleysols to those on Podzols. However, Gleysols have higher share of maize. Gleysols are hydromorphic soils, of which the subsoil is wet for most part of the year, therefore cultivating maize - a crop of high water and nutrient demand can be regarded an appropriate practice from pedological viewpoint on areas with light to medium or medium-heavy texture.

It is worth emphasizing once again that while cultivation patterns of different soil types show slight variations, these variations do not reach the degree to be significant.

3.3. Crop systems in relation to pedoclimatic conditions of the Northern Sub-Continental climate zone

Kastanozems have significantly different cropping pattern from all other soil types, which are cropped similarly to each other (Table 1., Figs. 3, 4). High share of maize and oil crops on Kastanozems present the difference from cropping on other soils. Kastanozems are considered to be the best soils in the region, with good structure, favorable water retention and conductivity characteristics and rich nutrient reserves. Furthermore these soils situate on the southern parts of the climate zone making it favorable for crops with higher temperature needs. The areal share of maize cultivation on Kastanozems is so high, that it alone shifts the average value of corn for the entire region. As a result, the share of maize on all other soil types differs significantly. Oil crops have relatively high share on Kastanozems too. From the viewpoint of climatic suitability, rapeseed is the main oil crop to grow in this zone. Rapeseed, along with maize, is among the

Peer) reviewing PDF | (2019:06:38280:2:1:NEW 20 Mar 2020) 
238

239

240

241

242

243

244

245

246

247

248

249

250

251

252

253

254

255

256

257

258

259

260

261

262

263

264

265

266

267

268

269

270

271

272

273

274

275

276

277

most demanding crops regarding nutrient uptake, especially $\mathrm{P}$, of which high stock is available in Kastanozems. Cereals and root crops, on the other hand can be cultivated successfully on other soils too. Although Kastanozems would be their most suitable growing medium, higher economic return of oil crops and maize suppress cereal and root crop areas in this zone.

3.4. Crop systems in relation to pedoclimatic conditions of the Mediterranean Semi-Arid climate zone

Great variability of crop distribution by soil types is found in the Mediterranean Semi-Arid zone (Figs. 3, 4). Especially Acrisols, Calcisols, and Fluvisols show divergence from other soil types in their cropping patterns. Acrisols, soils with rather poor fertility and low $\mathrm{pH}$ are not preferred for cereal cultivation but have significantly higher share of oil crops than any other soil types. Sunflower is the predominant oil crop in this climate zone. Sunflower is tolerant to lower $\mathrm{pH}$, which makes Acrisols acceptable edaphic environment for sunflower especially in contrast to maize, but also to cereals in general, which prefer soils with rather neutral reaction. Calcisols, on the contrary, have a significantly lower share of oil crop (sunflower) and significantly higher share of cereals than the average share of Acrisols, Vertisols and Regosols. The cropping pattern of Fluvisols is significantly different from that of Acrisols and Vertisols too and these differences are caused by the low share of oil crops on Fluvisols. Both Calcisols and Fluvosols have higher shares of cereals, which is significantly higher on Calcisols, than those of all other soil types. Both Fluvisols and Calcisols are among the fertile soils of the region, although the fertility of Calcisols may be limited by the availability of trace elements, especially Fe and Zn. Nevertheless our analysis shows that the distribution of crops follow the pedoclimatic conditions in this climatic zone.

\subsection{Crop systems in relation to pedoclimatic conditions of the Southern subcontinental climate} zone

There are two types of soils of which the cropping pattern deviates from the typical pattern of the zone, namely Gleysols and Podzols (Table 1., Figs. 3, 4). Distribution of crops on Gleysoils significantly differs from that on Podzols, Histosols and Leptosols and the share of its maize growing area is significantly higher than that of any other soil type of the zone. This is explained by the hydromorphic features and consequent water regime of Gleysols. Cultivating maize on Gleysols can be successful under this climate, because water supply on Gleysols can be secured from groundwater also during the critical periods in July and August, when climatic drought is frequent and water demand of maize is the highest. Favoring maize to cereals on Gleysols have another pedoclimatic reason too. Gleysols are among the soils which are most prone to excess water, especially in early spring, which presents high risk in the cultivation. This risk can be lessened if spring crops with sowing time after the wettest period are cultivated. Majority of cereals are autumn plants under this climate, thus maize is an excellent alternative for that reason too. As the sowing time of maize is normally after the period of highest inland water risk, cultivating maize on Gleysosls can be regarded as a win-win situation. 
278 Podzols are situated in those parts of the Southern subcontinental climate zone, which has 279 relatively higher precipitation and consequent lower mean temperature. Probably this is one of 280 the reasons for their unique cropping pattern including high shares of cereals, which is different 281 from those of all other soil types in the climate zone, rather than their pedological properties. 282 Apart from the relatively high rate of cereals, root crops (predominantly potato) which are also 283 abundant in this zone have wide climatic suitability as well. However, in the case of root crops 284 edaphic suitability plays an equally important role too, as the loose topsoil structure of Podzols is 285 favorable for root crop.

286

287

288

289

290

291

292

293

294

295

296

297

298

299

300

301

302

303

304

305

306

307

308

309

310

311

312

313

314

315

316

317

3.6. Crop systems in relation to pedoclimatic conditions of the Mediterranean (temperate and sub-oceanic) climate zone

Calcisols and Podzols are the two soil types of which the cropping pattern differs from those of most other soils in the Mediterranean (temperate and sub-oceanic) climate zone (Table 1., Figs. $3,4)$. In fact, these are the two soils with the largest (Calcisols) and smallest (Podzols) area cover of agricultural land in this climate zone. Podzols are cultivated for oil crops in significantly higher share than any other soil type under this climate, and the areal share of root crops is also rather high on Podzols. Legumes, maize and cereals, on the other hand occupy relatively smaller areas, although not significantly smaller, than on other soils in the zone. We believe that this cultivation pattern is reflecting the suitability of Podzols for crops which require loose soil structure and have tolerance to moderately acidic $\mathrm{pH}$. Calcisols, being one of the most fertile soils in the zone is mainly cultivated for cereals and oil crops, which are also the two most abundant crop groups of the zone. Although the relative share of cereals is higher and oil crops is lower than the average of the zone, these differences are not significant. The same applies for the relatively larger areas of legumes. Maize, on the other hand is cultivated on significantly smaller shares of Calcisols, than of the average of the zone. This finding suggests, that cereals and oil crops are the main plants in the rotation, with legumes and root crops playing a smaller role, just like maize, which is less considered in this soil than on others.

\subsection{Crop systems in relation to pedoclimatic conditions of the Temperate mountainous climate} zone

Gleysoils are significantly different from all other soil types, due to their lower share of oil crops area and higher share of root crops (Table 1., Figs. 3, 4). One explanation for these findings might be related to the soil geographical and genetic origin of Gleysols. In mountainous areas Gleysols are mostly located on plots with flat topography, where underground water causes reducing conditions. Cultivated Fluvisols of river valleys in this zone can have similar conditions, apart from the constant groundwater influence resulting gleyic properties. While Fluvisols show similar cropping pattern to that characteristic for the whole of the climate zone, Gleysols are used significantly less for oil crop production and more for root crops. We belive that this is due to two reasons. On the one hand, Gleysols are not very suitable for rapeseed (the most common oil crop in this climate zone), particularly if the reductive layer is at shallow to

Peer) reviewing PDF | (2019:06:38280:2:1:NEW 20 Mar 2020) 
318 medium depth, because rapeseed needs rather deep rooting zone free of hydromorphism.

319 Rapeseed requires good, fertile soil with high or medium $\mathrm{pH}$ values and it doesn't tolerate

320 compacted soils. These two phenomena are characteristic for the Gleysols in the mountainous

321 regions of Europe. Furthermore long winter and excessive snow cover, which are frequent in this

322 region, are not desirable. Because of the unsteady level of the yield, the successful cultivation of

323 this crop is not assured.

324 On the other hand potato (the most common root crop in this climate zone) finds suitable

325 compartments on Gleysols where gleyic properties are below the top soil layer. Potato

326

327

328

329

330

331

332

333

334

335

336

337

338

339

340

341

342

343

344

345

346

347

348

349

350

351

352

353

354

355

356

357 appreciates cool temperature and balanced climate and tolerates soil acidity too. However, this crop demands good soil management, for which the technology and traditions are available in this region. Regarding climatic conditions sugar beet production in general can be successful too, as water requirements of sugar beet can be satisfied (Supit et al. 2010) and Gleysoils might be suitable to grow the beet after ameliorative soil management, including drainage (as the most important action to reduce the influence of water) loosing, liming and good seedbed preparation. One should also always keep in mind that agricultural land is rather rare in this climate zone of mountainous land. Therefore local cropping practices - which traditionally are geared towards satisfying local consumption mainly of potato - can diverge the overall picture to a great degree. Rootcrops on Gleysosls are concentrated in the Northern Alps and the central Carpathians. Overpresentation of root crops in this climate zone (Fig. 3) is due to the wide-ranging potato cultivation on these areas with relatively higher share of agricultural land, compared to other areas in this climate zone.

\subsection{Crop systems in relation to production suitability in Hungary}

Sowing areas of all three examined crops increase by the improving soil quality (Fig. 5). Proportion of wheatland increases from 20 to $25 \%$ on areas from low to very high wheat productivity. The increase of relative sowing area of maize on higher quality soils is even larger than that of wheat. While less than $10 \%$ of low maize-productivity soils are actually used for maize cultivation, this share is above $35 \%$ on soils which are very highly productive and most suitable for maize. Although sunflower has the smallest sowing area among the three major crops in Hungary, the relative increase of sunflower land on soils from medium to very high suitability are the largest among them.

\section{Discussion}

Pedoclimatic conditions are considered in their complexity by farmers during their cropping practices across Europe. For instance oilcrops are cultivated on relatively high share of Podzols in Mediterranean (temperate-sub oceanic) and low share of Podzols in southern sub-continantal zone, meaning that similar specific soil conditions are considered together with the prevailing 
358

359

360

361

362

363

364

365

366

367

368

369

370

371

372

373

374

375

376

377

378

379

380

381

382

383

384

385

386

387

388

389

390

391

392

393

394

395

396

397

climatic conditions. This fact underlines the adequacy of the approach to study cropping systems by pedoclimatic conditions. Other good examples of soil-based farming include rootcrop production on Histosols in the Atlantic climate zone, maize production on Gleysosls of the Southern sub-continental climate, cultivating cereals on Podzols of the Sub-Oceanic climate zone, which all can be regarded as a "farming by soil" practice, which can be documented also on this coarse scale of analysis.

The fact that both zonal and azonal soils are among the soil types that might be cropped differently from the main cropping pattern of the given regions show that both climatic factors and soil conditions have important roles in selecting the most suitable crop. As Sicat et al (2005) found in a study area in India, farmers' perception on land suitability is largely based on their knowledge on texture, colour and rooting depth, attributes which also serve as classification criteria in soil taxonomy. Nevertheless, we have strong reasons to believe that in Europe soil suitability-based cropping is not practiced to its full potential over the continent at the moment. For example our finding suggests that production area of legumes are not fully adapted for the local pedoclimatic conditions in some zones (eg. Temperate mountainous, Southern Subcontinental). We assume that the reason for this is not always the balanced placement of legumes with regular return after long periods to the crop rotation, but because legumes are considered mostly "only" as an interim crop between the preferred ones. Legume crops have positive rotational effects that need to be evaluated at rotational level. The reduction in the use of mineral $\mathrm{N}$ fertilizers in legume-supported rotations due to biological N2-fixation is the main resource benefit, which, in addition reduces greenhouse gas emissions too. Pea and Faba beans for example are relevant alternatives to soybeans in the European cropping systems and livestock diets, since they can be grown across Europe in the different pedoclimatic zones. Probably including legumes to the rotations based on pedoclimatic conditions would enhance the overall agronomical output too. However, cropping which is desirable from agronomic viewpoint do not necessarily meet the profitability targets of the farm enterprises. In order to utilize the positive agronomic and environmental benefits, the remaining gross margin deficit of legumes should be compensated or further improved e.g. with the development of new value chains and markets, improvements in agronomy and breeding. Nevertheless, the agronomic and economic performance of legumes can only be adequately evaluated when all rotational effects are taken into account, which requires the analysis of time series data, which was not available for our study.

Findings of farming in pedocimatic zones under the Atlantic climate underlines that economic drivers are decisive when farmers adopt their cropping (eg. oil crops on Albeluvsiols), however soil suitability is considered too and may result in win-win situations for the economic return of crop production and management based on soil suitability (root crops on Histosols; cereals on Arenosols).

The national scale assessment further proved that soil suitability is a major factor when farmers choose crops to cultivate. The general tendency of "higher crop specific soil productivity $\rightarrow$ 
398 higher share of the adequate crop" applies to all crops. The consciousness of farmers are

399

400

401

402

403

404

405

406

407

408

409

410

411

412

413

414

415

416

417

418

419

420

421

422

423

424

425

426

427

428

429

430

431

432

433

434

435

436

437 reflected by the fact that wheat - a crop with the widest tolerance to climatic and soil conditions has the least variability in its area cover among suitability classes, while the sowing areas of maize and sunflower progressively grow on soils of higher suitability. The latter two crops have more particular water and nutrient needs. Maize, a crop of high water demand grows best on deep loamy soils rich in organic matter while sunflower a crop with average water demand prefers well drained soil with easy rooting conditions (Antal 2005). Although cultivation of crops on soils with different productivity show favorable distribution from the viewpoint of resource use efficiency, still, less productive land are also cultivated for the crops of our study. The lower share of cropping on low to medium quality land may have agronomic driver, namely that these major crops can be sawn in a rotation where they serve as side crops complementing the crops more suitable to grow under particular conditions. Nevertheless to reveal the full cropping pattern, including rotations needs further research.

When studying the options for optimization of cropping system for pedoclimatic conditions, we should also consider the changing climate, which influence the choice of cropping. The tendency of increased yield variability has been experienced in many regions of Europe in the last decades. Projections forecast more deteriorating agro climatic condition in terms of increased drought stress and shortening of the active growing season, which, in some regions become increasingly squeezed between a cold winter and a hot summer. Climatic changes in general are likely to shift the zonation of optimal production areas for specific crops within the EU. This tendency has implications for soil based cropping as well. Water management of soil becomes even more important aspect of farming. Soil with advantageous hydraulic properties, like Phaeozems, Chernozems and certain Luvisols and Cambisols will be the prime areas for cash crop productions. Farmers in regions of shifting climate can adopt their practices by learning the experiences from areas where suboptimal conditions has been experienced for long. In this regard the adaptability of European farmers is already demonstrated. When looking at the time series statistical data of crop cultivation (Eurostat 2017) we can assume that tendencies driven by policy incentives or climate change can restructure the crop composition of pedoclimatic zones rather rapidly. To extend our study towards consideration of climate change impact and for cropspecific analysis with regional to local relevance, an analysis based on detailed agroclimatic and agropedogenic categories is recommended. As the applicability of data used in our study is limited to continental scale assessment and for one country only, such a future study shall consider more detailed climate and soil maps, both regarding spatial and thematic resolution. Improvement of thematic content of the continental data in the future by including crop-specific productivity maps (like done in the country analysis) will help to overcome the main limitation of the current continental scale study too, thus can enhance the current results for Europe which are based on pedological reasoning. 


\section{Conclusions}

439 Consideration of ecological conditions, including soils is key to the success and sustainability of 440 farming. Our analysis highlights the main features of farming by soil in European pedoclimatic 441 zones and in Hungary. Results suggest, that farmers in general, consciously take pedoclimatic 442 condition of farming into account when selecting their cropping patterns. In other words, 443 pedoclimatic conditions of cropping are respected and farming by soil is a common practice in 444 all the different climatic regions of Europe. Our findings reveal, that within distinct climatic 445 zones, soil conditions are decisive for selecting crops, and this selection follows the spatial 446 pattern of soil distribution (Fig. 6.). On the other hand, while land users need to optimize their 447 cropping systems for the prevailing ecological conditions, economic motivations may alter the 448 cropping practice. Our study also highlights that, this actually happens, and while European 449 farmers crop according to the pedoclimatic conditions of their farms, economic considerations 450 may override the ecological consideration of farming.

451 Future direction in the greening of the Common Agricultural Policy should include incentives 452 that promote the optimization of soil resources use for the most profitable option that consider 453 the local pedoclimatic conditions as well.

\section{Acknowledgements}

This project received funding from the European Union's Horizon 2020 research and innovation programme under grant agreements No. 635750 (Interactive Soil Quality Assessment in Europe and China for Agricultural Productivity and Environmental Resilience), No. 67744 (Testing and promoting adaptation of soil-improving cropping systems across Europe) and No. 818346 (SinoEU Soil Observatory for Intelligent Land Use Management).

\section{References}

Antal, J. (Ed.) 2005. A növénytermesztés alapjai (Crop breeding principles) Mezögazdasági

Kiadó (Agricultural Publishing) Budapest, p 328.

Bongiovanni, R, Lowenberg-Deboer, J. 2004. Precision Agriculture and Sustainability. Precision Agriculture 5 (4) 359-387 DOI: 10.1023/B:PRAG.0000040806.39604.aa

EC 2003. European Soil Database (distribution version v2.0). European Commission Joint Research Centre, Italy. Available at https://esdac.jrc.ec.europa.eu/resource-typeleuropean-soildatabase-soil-properties

476 
477 EUROSTAT 2020. LUCAS - Land use and land cover survey. In. Eurostat - Statistics

478 Explained. https://ec.europa.eu/eurostat/statistics-explained/ (last accessed: March 2020)

479

480 Everitt, BS, Hothorn, T. 2010. A Handbook of Statistical Analysis with R (2nd ed.). Boca Raton,

481 London, New York: CRC Press, Taylor \& Francis Group.

482

483

484

FAO, ISSS, ISRIC. 1998. World reference base for soil resources.World Soil Resources Report

485

486 84, Rome.

487

Hartwich, R, Baritz, R, Fuchs, M, Krug, D, Thiele, S. 2005. Erläuterungen zur

Bodenregionenkarte der Europäischen Union and ihrer Nachbarstaaten 1:5,000,000 (version 2.0).

488 Hannover: Bundesanstalt für Geowissenschaften und Rohstoffe (BGR).

489

490

Ittersum, van MK, Rabbinge, R. 1997. Concepts in production ecology for analysis and

491 quantification of agricultural input-output combinations. Field Crops Research 52(3): 197-208

492

493

494 DOI: $10.1016 / \mathrm{S} 0378-4290(97) 00037-3$

Joglekar, A.K.B., Wood-Sichra,U., Pardey, P.G. 2019. Pixelating crop production:

495 Consequences of methodological choices. PLOS ONE 14(2): e0212281.

496

497

498

499

https://doi.org/10.1371/journal.pone.0212281

500

501

Lichtfouse, E, Navarrete, M, Debaeke, P, Véronique, S, Alberola, C. 2009. Sustainable Agriculture. Springer.

502

Meyer, D, Zeileis, A, Hornik, K. 2003. Visualizing independence using extended association

503 plots. Proceedings of the 3rd International Workshop on Distributed Statistical Computing, K.

504 Hornik, F. Leisch, A. Zeileis (eds.), ISSN 1609-395X. Available at https://www.r-

505

506 project.org/conferences/DSC-2003/Proceedings/MeyerEtAI.pdf

507

Meyer, D, Zeileis, A, Hornik K. 2006. The Strucplot Framework: Visualizing Multi-Way

508 Contingency Tables with ved. Journal of Statistical Software 17(3): 1-48 DOI:

509

510 10.18637/jss.v017.i03

511

Meyer, D, Zeileis, A., Hornik K. 2016. Visualizing Categorical Data. R package version 1.4-3.

512

513 Oksanen, J, Blanchet, FG, Friendly, M, Kindt, R, Legendre, P, McGlinn, D, Minchin, PR, 514 O'Hara, RB, Simpson, GL, Solymos, P, Stevens, MHH, Szoecs, E, Wagner, H. 2017. Vegan:

515 Community Ecology Package. R package version 2.4-3. Available at https://CRAN.R-

516 project.org/package $=$ vegan

517 
518 Pretty, JN 1997. The sustainable intensification of agriculture. Natural Resources Forum 21 (4):

519 247-256 DOI: 10.1111/j.1477-8947.1997.tb00699.x

520

521

522

523

524

525

526

527

528

529

530

531

532

533

534

535

536

537

538

539

540

541

542

543 You, L, Wood-Sichra, U, Fritz, S, Guo, Z, See, L, and Koo, J. 2014. Spatial Production

544

545

546

547

548

549

550

551

552

553

554

555

Sicat, R.S., Carranza, E.J.M., Nidumolu, U.B., 2005. Fuzzy modeling of farmers' knowledge for land suitability classification, Agricultural Systems, 83 (1) 49-75

Supit, I., van Diepen, C.A., Boogaard, H.L., Ludwig, F., Baruth, B., 2010. Trend analysis of the water requirements, consumption and deficit of field crops in Europe, Agricultural and Forest Meteorology, Volume 150, Issue 1, Pages 77-88,

Tilman, D, Cassman, KG, Matson, P.A, Naylor, R, Polasky, S. 2002. Agricultural sustainability and intensive production practices. Nature 418: 671-677 DOI: 10.1038/nature01014

Tóth, G. 2009. Hazai szántóink földminősítése a D-e-Meter rendszerrel (Evaluation of cropland productivity in Hungary with the D-e-Meter land evaluation system) Agrokémia és Talajtan. 58. (2.) pp. 227-242

Tóth, G, Gardi, C, Bódis, K, Ivits, É, Aksoy, E, Jones, A, Jeffrey, S, Petursdottir, T, Montanarella L. 2013. Continental-scale assessment of provisioning soil functions in Europe. Ecological Processes. 2 (32): 1-18 DOI: https://doi.org/10.1186/2192-1709-2-32

Tóth G., Tóth B., Pásztor L., Fodor N., Hermann T., Kocsis M., Máté F., Szatmári G., Laborczi A., Takács K., Sieglerné Matus J. 2018. Földminőség (Land quality). in: Kocsis K. (ed.) 2018. Magyarország Nemzeti Atlasza (National Atlas of Hungary). MTA CSFK Földrajztudományi Intézet, Budapest 187 p

Allocation Model (SPAM) 2005 v2.0. Available at http://mapspam.info

van Zanten, B, Verburg, PH, Espinosa, M, Gomez-y-Paloma, S, Galimberti, G, Kantelhardt, J, Kapfer, M, Lefebvre, M, Manrique, R, Piorr, A, Raggi, M, Schaller, L, Targetti,S, Zasada, I, Viaggi, D. 2014. European agricultural landscapes, common agricultural policy and ecosystem services: a review. Agronomy for Sustainable Development 34 (2): 309-325 DOI: 10.1007/s13593-013-0183-4

Wezel, A, Casagrande, M, Celette, F, Vian JF, Ferrer, A, Peigné, J. 2014. Agroecological practices for sustainable agriculture. A review. Agronomy for Sustainable Development (34) 1: 1-20 DOI: 10.1007/s13593-013-0180-7 
556 Zeileis, A, Meyer, D, and Hornik, K, 2007. Residual-based Shadings for Visualizing

557 (Conditional) Independence. Journal of Computational and Graphical Statistics, 16(3): 507-525

558 DOI: $10.1198 / 106186007 \mathrm{X} 237856$ 


\section{Table 1 (on next page)}

Differences in farming systems between Reference Soil Groups (RSGs) in different climate Zones of Europe (result of Chi square statistics, $p \leq 0.05$ ) 


\begin{tabular}{|c|c|c|}
\hline Climate zones & RSGs & other RSGs with significantly different farming systems \\
\hline \multirow[t]{2}{*}{ 1. Atlantic } & Histosols: & $\begin{array}{l}\text { Albeluvisols, Arenosols, Cambisols, Gleysols, Luvisols, } \\
\text { Leptosols }\end{array}$ \\
\hline & Arenosols: & Albeluvisols, Fluvisols, Histosols \\
\hline 2. Sub-oceanic & \multicolumn{2}{|c|}{ There is no significantly difference between any RSG } \\
\hline \multicolumn{3}{|l|}{ 3. Northern-sub oceanic } \\
\hline \multirow[t]{3}{*}{ 4. Mediterranean semi-arid } & Acrisols: & Significantly different from all other reference soil groups \\
\hline & Calcisols: & Acrisols, Regosols, Vertisols \\
\hline & Fluvisols: & Acrisols, Vertisols \\
\hline \multirow[t]{2}{*}{ 5. Southern sub-continental } & Podzols: & Significantly different from all other reference soil groups \\
\hline & Gleysols & Histosols, Leptosols, Pozols \\
\hline \multirow[t]{2}{*}{$\begin{array}{l}\text { 6. Mediterranean (temperate } \\
\text { and sub-oceanic) }\end{array}$} & Calcisols: & Fluvisols, Luvisols, Podzols \\
\hline & Podzols: & Calcisols, Cambisols, Leptosols \\
\hline 7. Temperate mountainous & Gleysols & Significantly different from all other reference soil groups \\
\hline
\end{tabular}


Figure 1

Climate zones in Europe 
Boreal to Sub-Boreal

Atlantic

Sub-Oceanic

Sub-Continental (Northern)

Sub-Continental (Southern)

Mediterranean (Temperate and Sub-Oceanic)

Mediterranean (Semi-Arid)

Temperate Mountainous

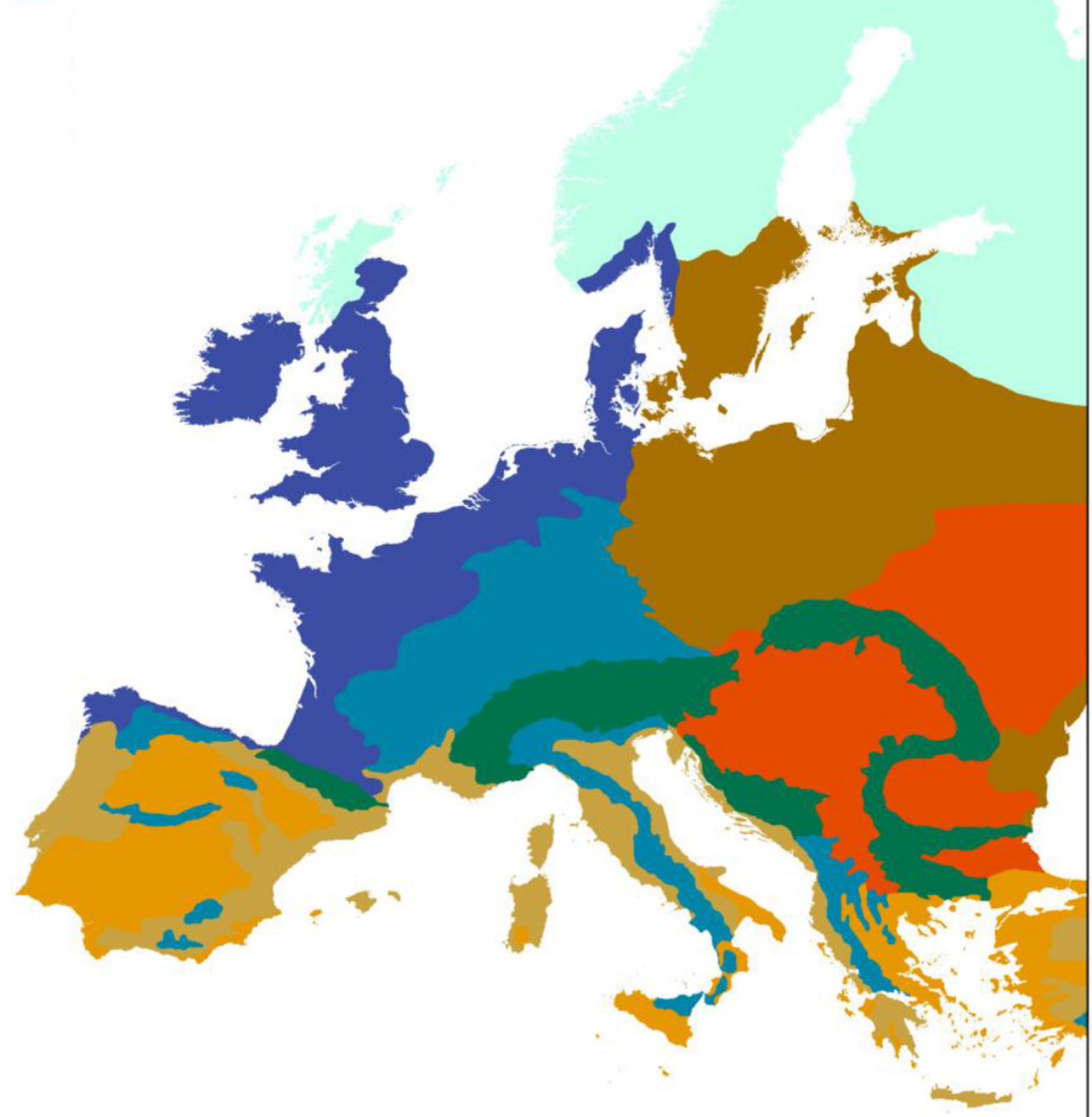




\section{Figure 2}

Crop-specific soil productivity in agricultural areas of Hungary

$A=$ wheat, $B=$ maize $C=$ sunflower, productivity score: $1=$ lowest, $100=$ highest productivity
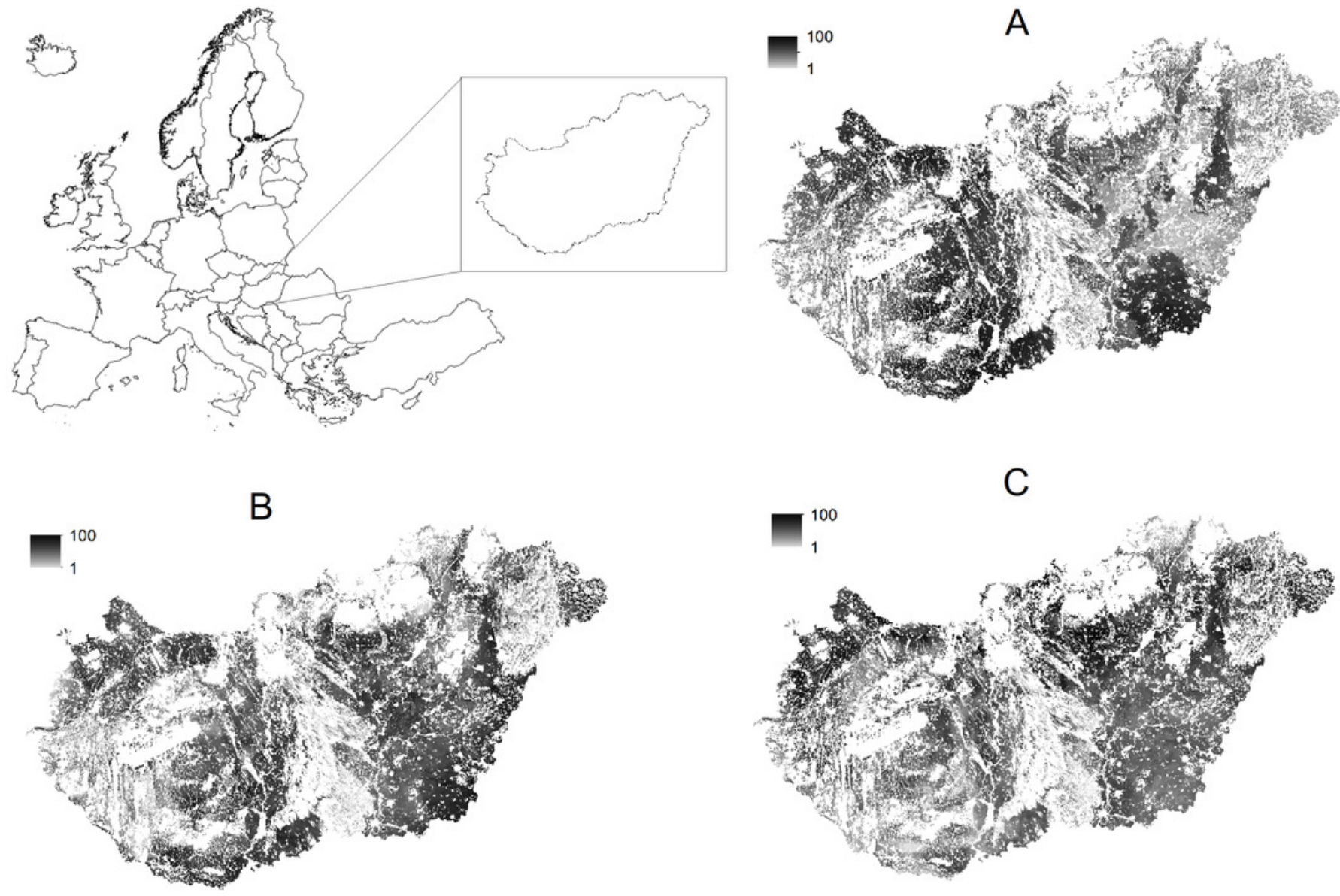
Figure 3

Dissimilarity indices matrix of cropping systems by Reference Soil Groups

(A) Atlantic climatic zone (B) Sub-Oceanic climate zone (C) Northern sub-continental climate zone (D) Mediterranean, semi-arid climate zone (E) Southern Sub-Continental climate zone (F) Mediterranean (temperate and sub-oceanic) climate zone (G) Temperate mountainous climate zone 
A

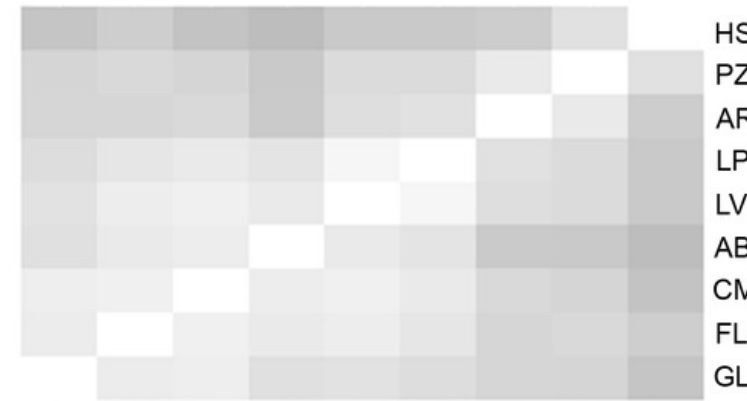

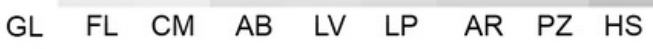

C

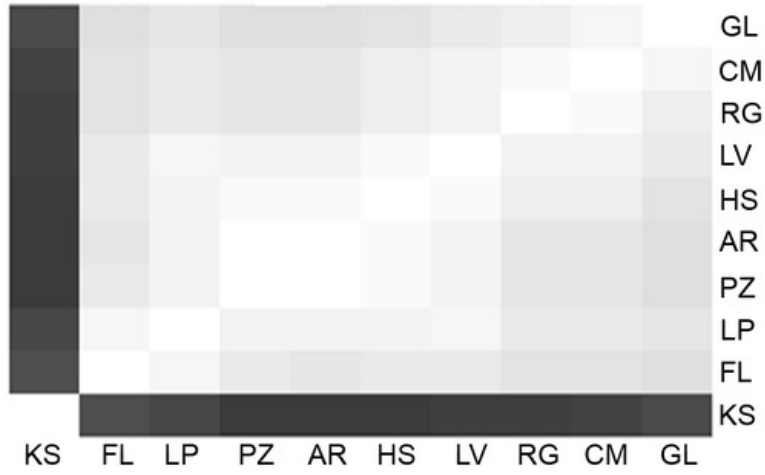

E

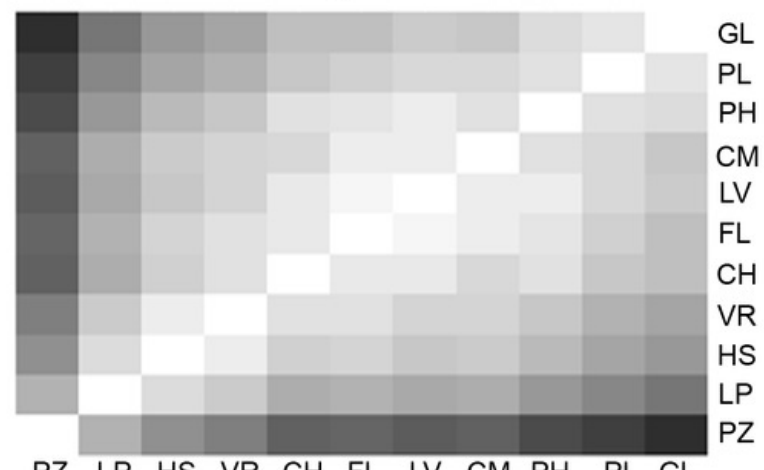

G
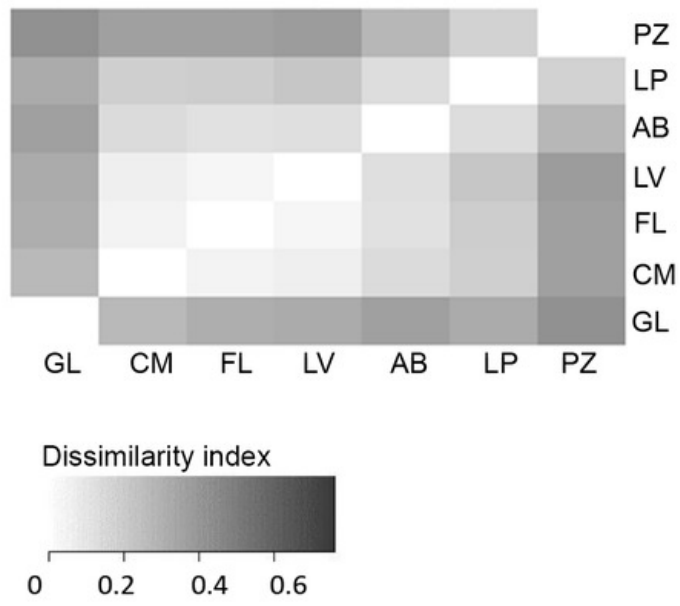

B

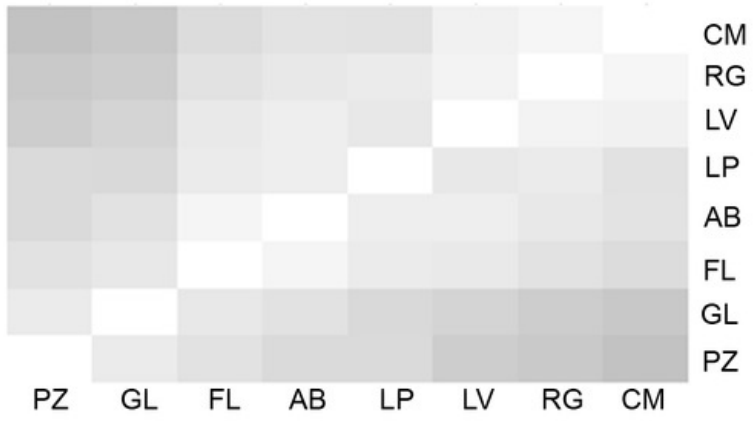

D

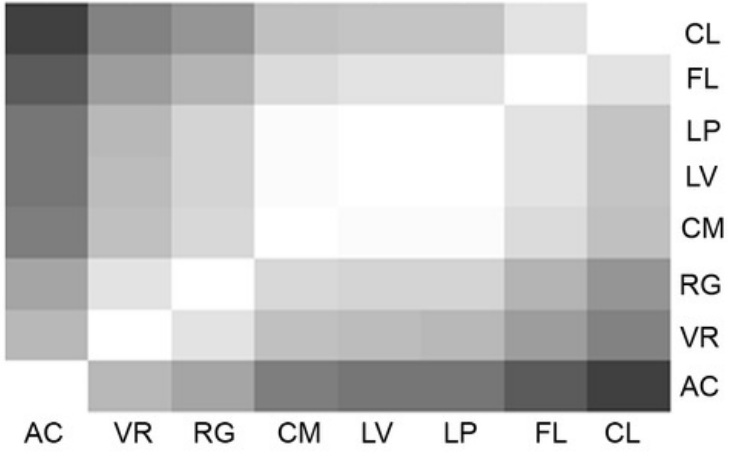

$\mathrm{F}$

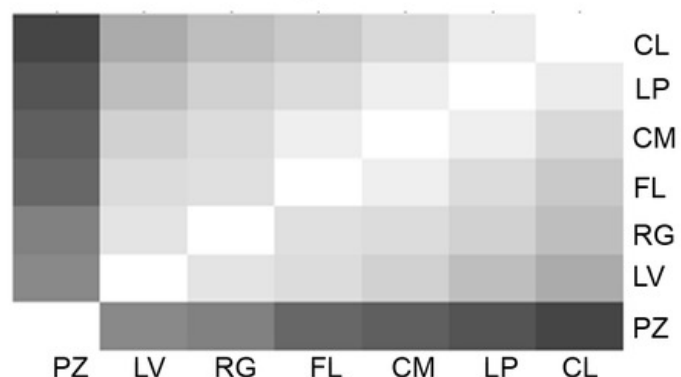

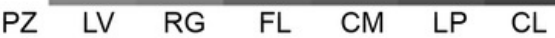

\begin{tabular}{|l|l|l|l|}
\hline Name of RSG & Code of RSG & Name of RSG & Code of RSG \\
\hline Albeluvisols & AB & Kastanozems & KS \\
\hline Acrisols & AC & Leptosols & LP \\
\hline Andosols & AN & Luvisols & LV \\
\hline Arenosols & AR & Phaeozems & PH \\
\hline Chernozems & CH & Planosols & PL \\
\hline Calcisols & CL & Podzols & PZ \\
\hline Cambisols & CM & Regosols & RG \\
\hline Cryosol & CR & Solonchaks & SC \\
\hline Fluvisols & FL & Solonetzes & SN \\
\hline Gleysols & GL & Umbrisols & UM \\
\hline Gypsisols & GY & Vertisols & VR \\
\hline Histosols & HS & & \\
\hline
\end{tabular}


Figure 4

Conditional association plots of cropping systems by Reference Soil Group s

Atlantic climatic zone (B) Sub-Oceanic climate zone (C) Northern sub-continental climate zone (D) Mediterranean, semi-arid climate zone (E) Southern Sub-Continental climate zone (F) Mediterranean (temperate and sub-oceanic) climate zone (G) Temperate mountainous climate zone 
A

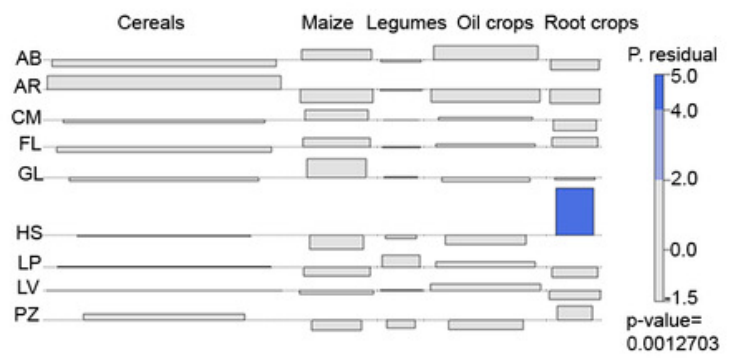

B

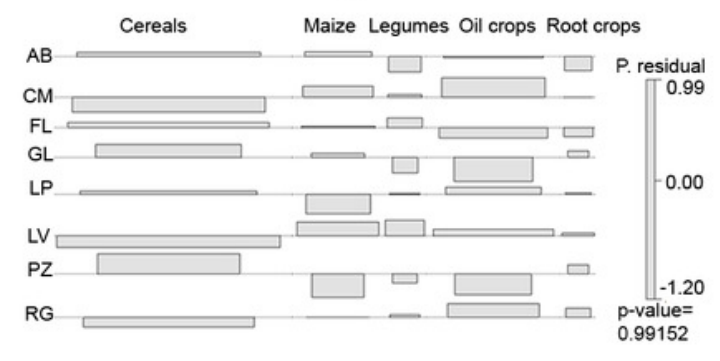

C

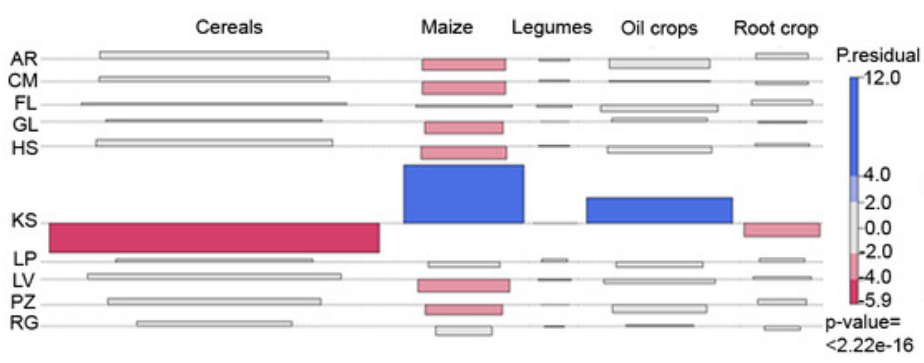

E

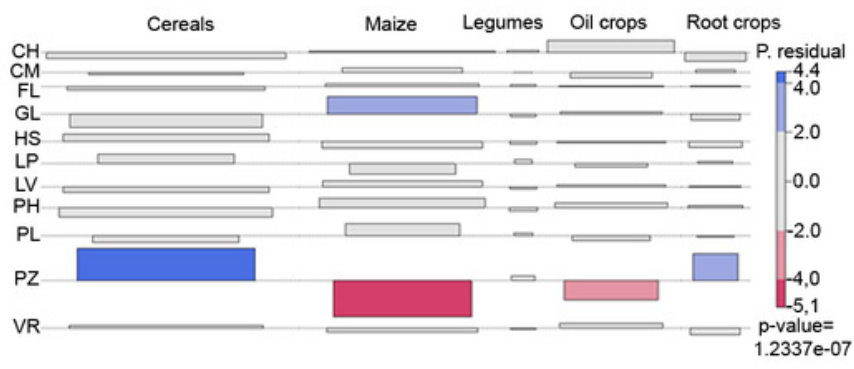

G

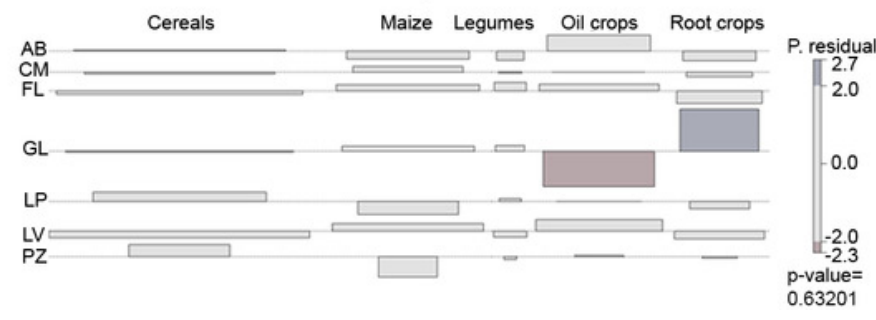

D

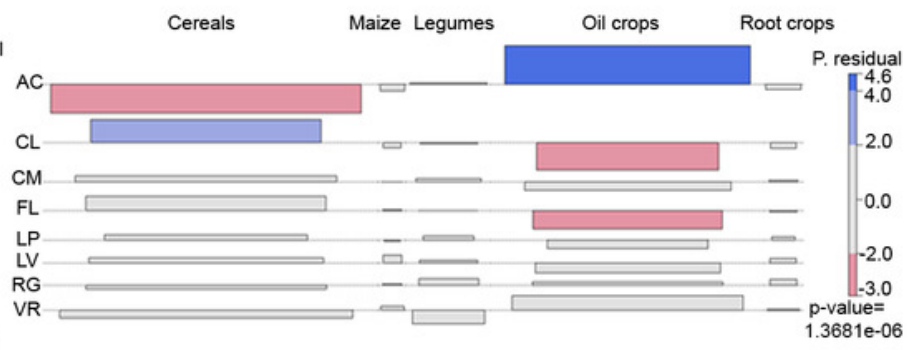

ixtilices

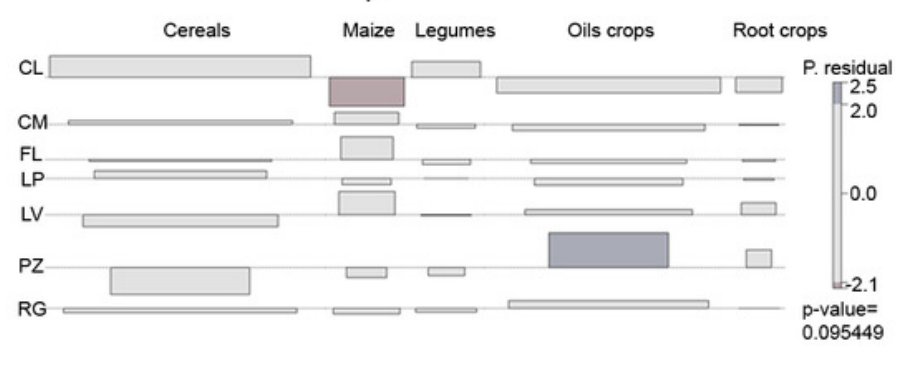


Figure 5

Relative distribution of major crops by crop-specific soil productivity classes in Hungarian croplands
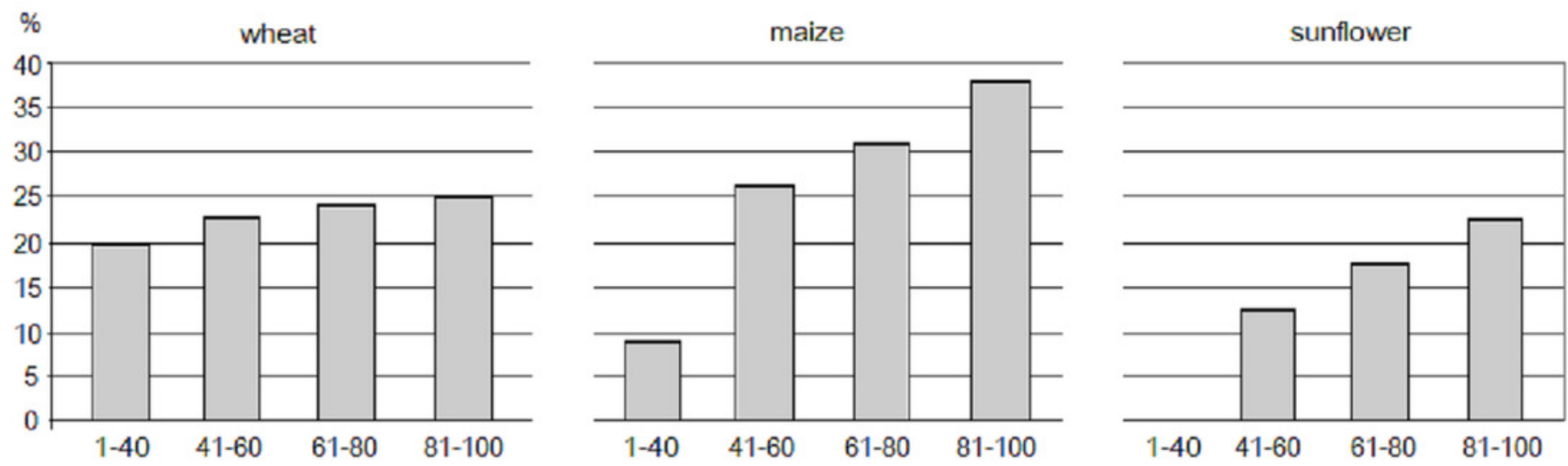


\title{
Figure 6
}

\section{Areas of specific cropping patterns in pedoclimatic regions of Europe.}

\author{
(A) cereals (B) maize (C) oil crops (D) root crops
}

Blue: soils with significantly larger sawing areas compared to the common areal share of this crops in the climate zone.

Red: soils with significantly smaller sawing areas compared to the common areal share of this crops in the climate zone.

Light blue: soils with significantly larger sawing areas compared to those of only some of the other soils in the climate zone.

Rose: soils with significantly smaller sawing areas compared to those of only some of the other soils in the climate zone. 
A

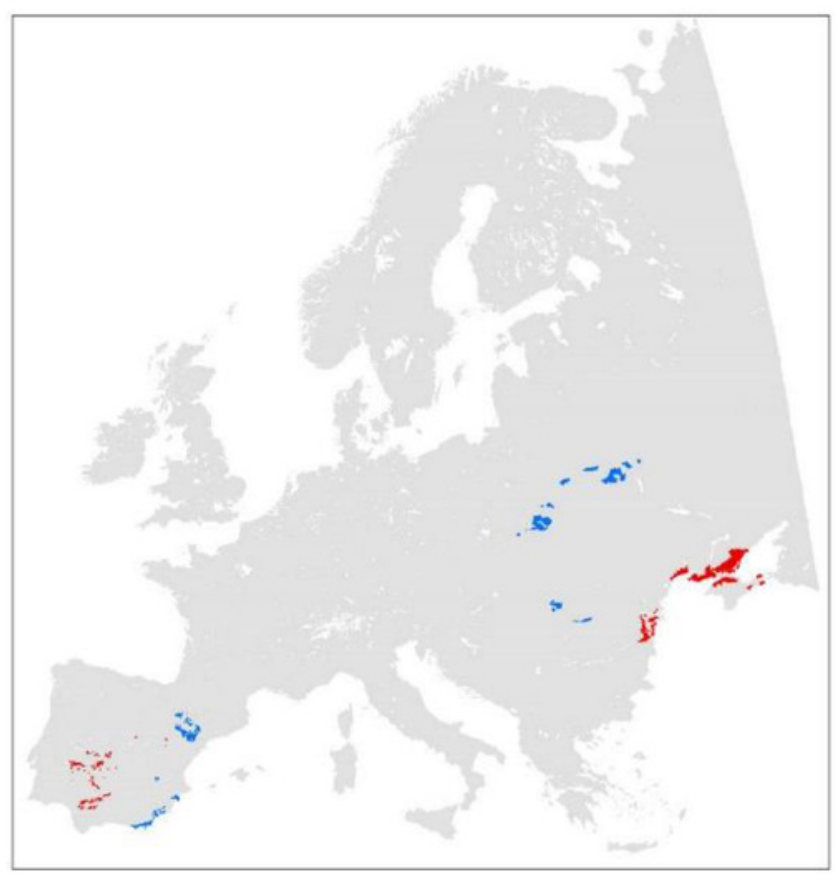

C

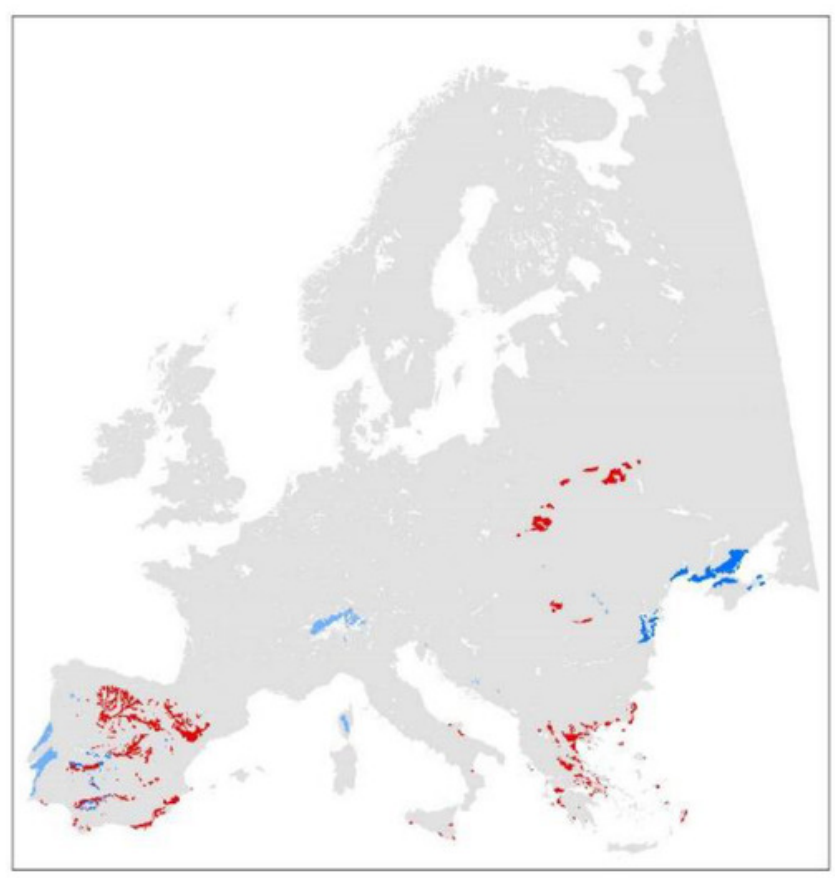

B

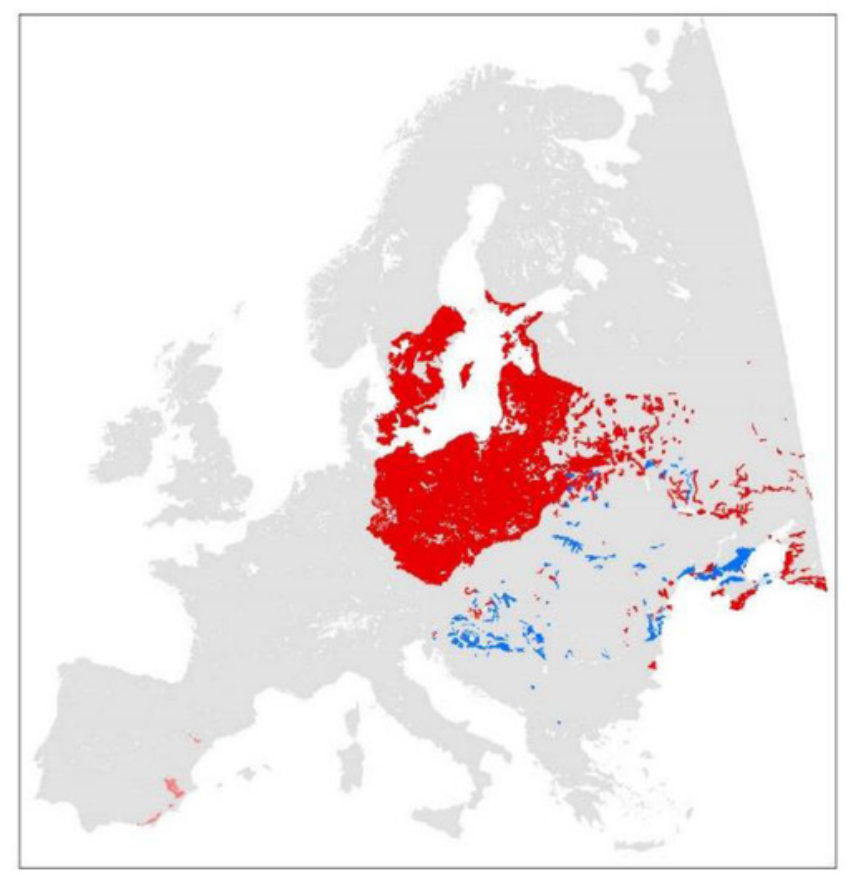

D

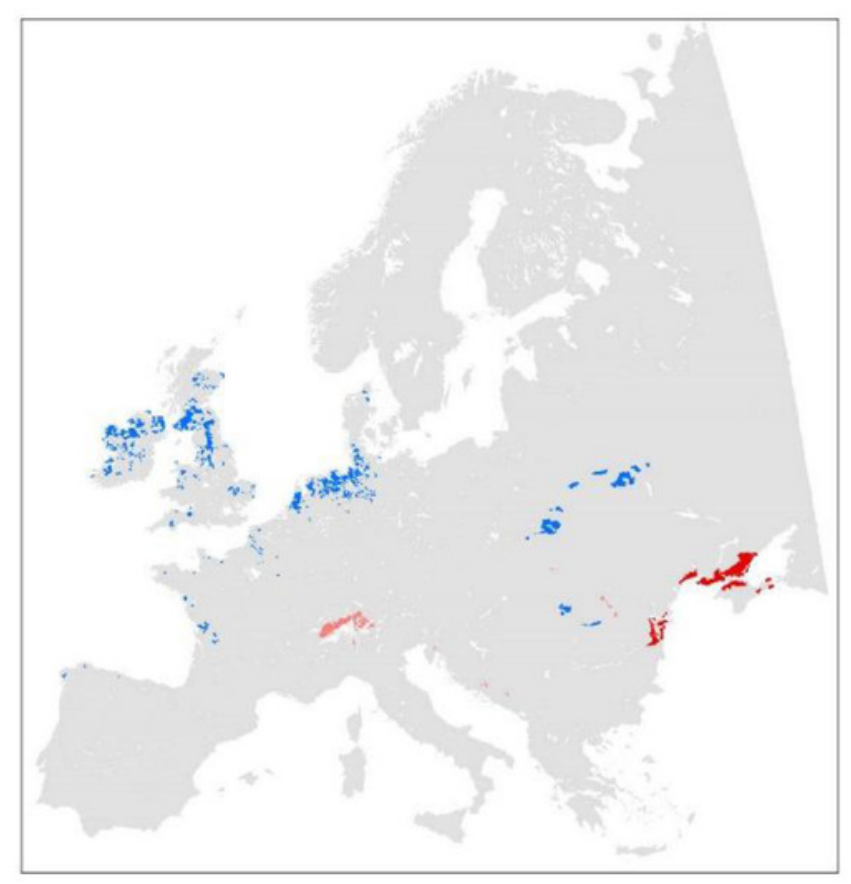

